\title{
CORRECTION
}

\section{Correction to "Changes over time in means of suicide in Canada: an analysis of mortality data from 1981 to 2018"}

CMAJ has been made aware of an error that occurred in the Mar. 8, 2021, issue. ${ }^{1}$

In the second paragraph on the third page, the second sentence read " $A$ total of 142343 suicide deaths of individuals aged 10 years and older occurred in Canada from 1981 to 2008." This should have read " $A$ total of 142343 suicide deaths of individuals aged 10 years and older occurred in Canada from 1981 to 2018."

This has been corrected at cmaj.ca.

- Cite as: CMAJ 2021 August 30;193:E1359. doi: $10.1503 /$ cmaj. 211420

\section{Reference}

1. Liu L, Capaldi CA, Orpana HM, et al. Changes over time in means of suicide in Canada: an analysis of mortality data from 1981 to 2018. CMAJ 2021; 193:E331-8. 